\title{
How has the prevalence of cigarette smoking changed among Australian adults? Trends in smoking prevalence between 1980 and 2001
}

\author{
V White, D Hill, M Siahpush, I Bobevski
}

Tobacco Control 2003;12(Suppl II):ii67-ii74

See end of article for authors' affiliations

......................

Correspondence to: V White, Deputy Director, Centre for Behavioural Research in Cancer, Cancer Control Research Institute, The Cancer Council Victoria, 1 Rathdowne Street, Carlton, Vic 3053, Australia; vicki.white@ cancervic.org.au

\begin{abstract}
Objective: To examine trends in the prevalence of cigarette smoking between 1980 and 2001 among several different sociodemographic groups within the Australian population.

Method: National cross sectional surveys conducted by face to face interview every 3 years from 1980. Respondents were classified into five age groups and the occupation of respondents in the workforce were classified into one of upper or lower white collar or upper or lower blue collar.

Main outcome measure: Prevalence of smoking at least weekly.

Results: The prevalence of smoking in 2001 was lower than that found in 1980 and this was true for all sociodemographic groups. Among adults smoking prevalence decreased from $35 \%$ in 1980 to $23 \%$ in 2001 . The differential in smoking prevalence between men and women decreased between 1980 and 2001 . Although smoking was more common among younger Australians (<24 years) than older Australians throughout the study, the differential between age groups reduced. For all years except 1980, the proportion of smokers among upper white collar workers was significantly lower than in all other occupation groups.

Conclusion: There had been a continual decline in the prevalence of smoking among the Australian population since 1980. This decline had occurred across both sexes and in all age and occupation groups. Much of the decline in smoking prevalence between 1998 and 2001 was among blue collar worker group.
\end{abstract}

$\mathrm{T}$ obacco control in Australia today builds on nearly four decades of work in this area. Although the intensity and focus of activity in this area has changed dramatically over the years, each new campaign builds on past campaigns and on new or amended legislation that has changed the environment for smoking in Australia. It also occurs in a society where the prevalence of smoking has changed dramatically. ${ }^{1-8}$ In this paper we examine trends in the prevalence of tobacco use among Australian adults from 1980 to 2001-a period when tobacco control programmes advanced considerably.

A number of different measures are needed for tobacco control programmes to be effective at reducing the prevalence of tobacco use. These measures include banning the promotion of cigarettes, increasing the price of cigarettes, limiting the number of places where tobacco can be smoked, the presence of effective anti tobacco advertising, effective health warnings on tobacco products, and restricting adolescents' access to tobacco products. ${ }^{9-10}$ Australia has introduced all of these measures to varying degrees over the past 30 years. The introduction of health warnings on cigarette packs and cigarette advertisements was one of the first measures introduced in 1972. The health warning used at this time was fairly innocuous and was replaced in 1987 with one of four rotating warnings giving more concrete information about the health consequences of smoking. ${ }^{11}$ For example, one warning stated "Smoking causes lung cancer". In 1995 two new health warnings were introduced and health warnings and information needed to occupy $25 \%$ of the front of the cigarette pack and $33 \%$ of the back of a pack. The phone number of a national information line also needed to be carried on the cigarette pack. ${ }^{12}$

The next strategy employed in Australia to reduce the use of tobacco was the phasing out of direct advertising for cigarettes in the electronic media (radio and television) between 1973 and 1976. However, advertising in the print media, cinema, billboards, and sporting events was still available until the late 1980s, when these forms of advertising were banned. By 1991 $80 \%$ of the population was covered by legislation banning tobacco advertising and in December 1992 the Federal government passed legislation that phased out all other forms of cigarette advertising by $1995 .{ }^{11}$ Currently, only point of sale advertising is available to market cigarette brands in Australia.

One of the major planks of tobacco control programmes in Australia was the development of State based quit programmes and mass media public education programmes. These programmes arose from the success of the first major mass media quit smoking campaign in 1982/1983 in Australia's most heavily populated State (New South Wales). ${ }^{13-14}$ Public education campaigns promoted quitting and discouraged uptake and advocated for legislative controls on the advertising, sale, and use of tobacco products. Restrictions on smoking in public places began with bans on smoking on public transport in 1975 and the number of places with smoking restrictions increased in the late 1980s and 1990s. Federal government workplaces became smoke free in 1986 and the use of tobacco on Australian airlines was banned from 1987. By 2002 most Australian States and Territories had prohibited smoking in enclosed public spaces such as shopping centres and in cafes and restaurants while meals were being served. However, places such as hotels, bars, nightclubs, and gaming rooms were generally exempted from this legislation.

In an effort to restrict tobacco access to adults the legal age for purchasing cigarettes was increased from 16 to 18 in many States and by the late 1990s it was illegal to sell tobacco to people under the age of 18 in all Australian States. Significant real tax increases on the price of cigarettes was not an instrument of tobacco control in Australia until the early 1990s when the Federal government began to increase the excise levy on cigarettes every six months in line with the consumer price index. In 1999, the excise levied on tobacco changed

Abbreviations: NDSHS, National Drug Strategy Household Survey; SHS, Smoking and Health Surveys; CATI computer assisted telephone interviews; NTC, National Tobacco Campaign 
from a per weight basis to a per stick basis. As a consequence, tobacco manufacturers could not minimise the price of a pack of cigarettes by reducing each cigarette's weight and packaging more cigarettes in larger packs. This change in the system of taxing tobacco put an end to budget cigarettes in Australia (see Scollo et al this issue, for details on these changes to the taxation levied on cigarettes and their impact on tobacco use $\mathrm{e}^{15}$ ).

The assessment of the overall impact of the full range of tobacco control strategies has been informed by surveys reported by us previously. ${ }^{1-8}$ The results of these studies have suggested that the prevalence of smoking among Australian adults decreased throughout the $1980 \mathrm{~s}$ and stabilised at around $25 \%$ by the middle of the $1990 \mathrm{~s}^{8}{ }^{8}$ The latter years of the 1990s saw an increase in tobacco control activity throughout Australia, including a national advertising campaign and a change to the way tobacco was taxed (from weight per pack to a per stick basis). Wakefield et al (this issue) ${ }^{16}$ showed that the national advertising campaign that ran between June 1997 and September 2000 with varying intensity, effectively increased smokers' knowledge of the health risks associated with smoking and increased their intention to quit and number of quit attempts. It is, therefore, of interest to determine the prevalence of smoking in 2001 relative to earlier years. The trend data presented by Hill and colleagues previously were limited to sex specific age adjusted estimates. ${ }^{17}$ In this paper we use data from our previous studies to re-assess trends in smoking prevalence among men and women, five age groups, and different occupation groups between 1980 and 1998 (our last and as yet unpublished survey). To extend the trend line to 2001 we draw on data collected as part of the National Drug Strategy Household Survey (NDSHS).$^{18}$ This study commissioned by the Commonwealth Department of Health and Ageing is conducted by a large market research company and surveys a representative sample of Australian adults. As the method employed in the NDSHS was similar to that used in the studies reported by Hill and colleagues, we deemed it appropriate to combine these data sets.

\section{METHOD}

Data reported here are taken mainly from the Smoking and Health Surveys (SHS) conducted by the Anti-Cancer Council of Victoria. ${ }^{1-8}$ Data from the 2001 NDSHS conducted by the Commonwealth Department of Health and Ageing (formerly Commonwealth Department of Human Services and Health) were included in the data set to provide estimates of smoking in $2001 .{ }^{18}$ The method for each of these surveys is described in brief below. For a more detailed explanation of each study's methods the reader is referred to the original reports cited above. Although NDSHS data for the years 1995 and 1998 are not included in the analyses presented below, we compared estimates of smoking prevalence from the SHS and the NDSHS for these years to test our assumption that including 2001 NDSHS in the trendline was valid. The comparison of the two surveys for each of the survey years showed very similar estimates of adult smoking by the two surveys (1995: SHS $26 \%$, NDSHS 26\%; 1998: SHS 26\%, NDSHS $27 \%$ ).

\section{SHS: method, questions, and sample size}

The same large market research company carried out the sampling and interviewing for each survey as part of an omnibus survey they conducted. These procedures were the same in all surveys. In brief, interviews were conducted on the weekend with respondents within a census collector's district selected at random within specified strata that included State and rural/urban divisions. Within each collector's district an individual residence was chosen at random for the first contact with the adjacent house contacted next. Further adjacent households were approached until the required number of interviews for that collector's district was obtained (usually eight from approximately 200 households in each census collector's district). Once contact with a household was established, one person aged $\geqslant 14$ years or over was randomly selected for interviewing using the last birthday method. If the selected person was not available for interview three callbacks were made. The numbers of participants $>18$ years at each survey were in 1980,$3696 ; 1983,5087 ; 1986,8513 ; 1989$, 5314; 1992, 6304; 1995, 5149; and 1998, 7852. Approximately half the sample was male and the proportion of the sample in each of the five age groups (18-24, 25-29, 30-39, 40-59, 60+) reflected the proportion of the Australian population in these age groups.

\section{Smoking assessment}

Respondents indicated their smoking status by choosing a category from the following list: smoke cigarettes only; smoke cigarettes plus cigars or pipes, smoke cigars only (excigarettes); smoke pipes only (ex-cigarettes), smoke cigars only (never cigarettes), smoke pipes only (never cigarettes), ex-smoker (of cigarettes, pipes or cigars), and never smoker.

\section{NDSHS: method, questions, and sample size}

These surveys have been conducted mainly at three yearly intervals since 1985. Data from the 2001 survey provide estimates of current smoking prevalence among Australian adults.

In 2001 a large market research company conducted the field work for the study and collected the data using three methods: (a) face to face household interviews; (b) drop and collect questionnaires (interviewer contacted household, identified respondent, and left a questionnaire for them to complete by themselves); and (c) computer assisted telephone interviews (CATI). Only data collected by the first two methods are used in this paper as these data collection methods most closely matched those used for the SHS. In both data collection procedures, interviewers contacted the household and identified the respondent to complete the questionnaire. Interviewers then either administered the survey or gave the questionnaire to respondents to complete. In both situations questions assessing drug use (including tobacco and alcohol) were assessed by means of a self report questionnaire that could be completed in private and returned to the interviewer in a sealed envelope. The sample design involved a geographic stratification by State/Territory and Metropolitan/rest of State. The proportion of respondents from Metropolitan areas and from the rest of the State reflected the population distribution for these areas in each State. Respondents from smaller States were over represented in the national sample due to the desire to provide information for specific States from the survey. The sample allocation in each State was then divided into clusters with census collectors' districts forming the basis of these clusters.

Interviewers visited every third dwelling in their collector's district until 10 interviews were achieved. Once contact with a household was established one person aged $\geqslant 14$ years was randomly selected for interviewing using the last birthday method. If the selected person was not available for interview three callbacks were made. If the selected person was still not available the person with the next birthday or youngest male was substituted. For this paper only data from respondents $\geqslant 18$ who participated in a face to face interview or completed the drop and collect survey were used. The sample size was 23 376. Slightly more women than men were interviewed and again the proportions in each of five age groups matched the population distribution.

Questions on smoking

In the 2001 study smoking status was assessed by first asking respondents if they had ever tried a cigarette or smoked a full 
cigarette then asking respondents if they had smoked more than 100 cigarettes in their lifetime. Respondents indicating they had smoked more than 100 cigarettes were asked: "How often do you now smoke cigarettes, pipes, or other tobacco products?" and could indicate: "daily"; "at least weekly"; "less often than weekly"; "not at all but I have smoked in the past 12 months", or "not at all and I have not smoked in the past 12 months".

\section{Weighting}

To correct for any over and under sampling in different States and age and sex groups, data were weighted to the same population estimates for each survey. As we were interested in comparing data over a 21 year period it was decided to age standardise to the 2001 population. Data from the 2001 Australian census were used to determine the age and sex population distributions for each State (the Australian Capital Territory was included with New South Wales and the Northern Territory was included with South Australia) and data from all survey sets were weighted to this population distribution. The age groups used for weighting were 18-24, 25-29, 30-39, 40-59, and 60+.

\section{Definition of current smoking to estimate prevalence}

As indicated above, the two surveys used a different measure to assess smoking status. The question used in the 2001 NDSHS assessed weekly smoking and daily smoking. The smoking status question used in the SHS did not include an indicator of daily or weekly smoking. Rather, these surveys relied on participants' description of themselves as smokers of tobacco or not. In 1998, the Anti-Cancer Council of Victoria conducted a study to calibrate questions assessing daily and weekly smoking against the SHS smoking status question. ${ }^{19}$ This study found that defining regular smokers as those who smoke at least weekly (combining daily smokers and people who smoke at least once a week) gives approximately the same proportion of smokers $(24.9 \%)$ as determined by the question in the SHS $(25.3 \%)$. We therefore defined regular smokers in the NDSHS surveys as those adults who smoked at least on a weekly basis.

\section{Consumption of tobacco per capita}

For taxation purposes until 1998, the Customs and Excise Department of the Commonwealth Government was supplied with the precise quantity of tobacco sold legally in Australia each month. From 1998, data on the quantity of loose tobacco were no longer available because of confidentiality issues that allowed manufacturers to refuse the release of data. As a consequence the volume of loose tobacco sold has been estimated. When excise rates for cigarettes changed to a per stick basis from November 1999, the quantity of tobacco sold was estimated using the number of cigarettes sold and assuming a cigarette weight of $0.725 \mathrm{~g}$. To determine the consumption of tobacco per capita, the total amount of tobacco products sold each year in Australia was calculated and this annual weight divided by the population of Australia over the age of 15 for that year. ${ }^{20}$ This denominator was used as 16 was the legal age for buying cigarettes in most Australian States until the early to mid-1990s. We believe the inclusion of 15-17 year olds in the per capita estimates would make little difference to the estimates and would have little impact on the pattern of long term trends reported here.

\section{Analyses}

Cases with missing data on questions assessing smoking status were excluded from these analyses. Missing data were minimal across survey years, ranging from a low of $1 \%$ in 1992 to a high of $2.5 \%$ of all cases in 1998 . The distribution of missing cases for each of the demographic variables investigated in this report followed the distribution of non-missing cases for these variables. The proportion of smokers was defined as those who had smoked at least one cigarette on a weekly basis for 2001, while for all other years respondents who classified themselves as a smoker of cigarettes were defined as smokers. Age was categorised into five groups: 18-24, 25-29, 30-39, $40-50$, and $60+$ years. The indicator of socioeconomic status was the respondent's occupation. Occupation was categorised into five categories: "upper white collar", which includes professionals, owners or executives, and farm owners; semiprofessionals, "lower white collar", which includes sales and other white collar; "upper blue collar", which includes skilled workers; and "lower blue collar", which includes semi-skilled, unskilled, and farm workers. Respondents not currently in paid employment were classified as such and are treated separately from other groups. This group includes those engaged in domestic duties, students, retired people, and respondents looking for work. This method of classifying occupation was necessary because the SHS did not provide detailed information on the exact occupation of respondents. Therefore, we were unable to use standard occupational prestige scales that have been developed in Australia. The occupation information provided in the SHS categorised respondents' occupations into one of 12 occupational categories, which we collapsed into four groups as described above. The same 12 categories were used in all surveys. Although the occupational classification used here are crude, we believe it provides a good indicator of social class and that the relative class standing of the groups in 1980 would be the same as that found in 2001 .

The proportion of smokers in each survey year was calculated and changes in proportions over time were examined using logistic regression analyses. In these analyses, the main effect of year was first examined and if significant odds ratios and $95 \%$ confidence intervals (95\% CIs) were used to examine whether the proportion of smokers in 2001 differed significantly from that found in the previous survey. If the main effect of year was significant, interaction terms were included in the model to determine whether changes in smoking prevalence were consistent across sex, age, and work status groups. Separate models were constructed to test the significance of the interaction terms for: year and sex, year and age, and year and work status. If the interaction was significant separate logistic regression models were constructed for each level of the sociodemographic variable under investigation, enabling us to examine changes in tobacco use for each group in more detail. For each level of the sociodemographic variable under investigation, a model examining changes in smoking prevalence across years was constructed. In these models sex and, where appropriate, age were controlled statistically and 2001 was used as the comparison year. Thus, these models allowed us to test whether smoking prevalence in 2001 in each of the sociodemographic groups differed from that found in earlier years. In addition to these analyses for each sociodemographic variable we determined the odds ratios for smoking given that a respondent belonged to a particular social group for each survey year and compared the odds ratios for each level across years. By comparing the odds ratios obtained in each year using the $\mathrm{z}$ score test we could examine if the differential in smoking rates between members of different age or job status groups and the base group changed between 1980 and 2001 . For these analyses, the comparison groups were men for sex, 18-24 year olds for age, and upper white collar workers for job status.

\section{RESULTS}

Fig 1 shows the age standardised estimates of regular smoking among Australian adults over the age of 18 from 1980 to 2001 against per capita consumption of tobacco for each survey year. As can be seen, the prevalence of smoking has declined among Australian adults over this 21 year period. Between 


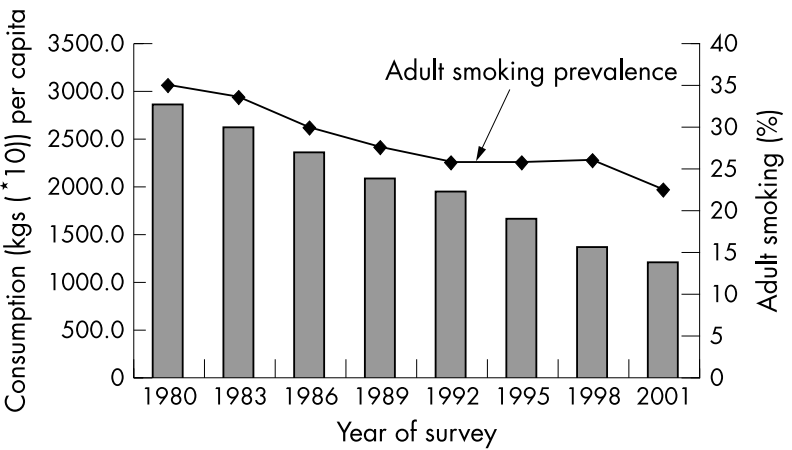

Figure 1 Estimates of smoking prevalence among the Australian population over the age of 18 from 1980 to 2001 obtained from the Smoking and Health Surveys (1980-1998) and National Drug Strategy Household Survey (2001) (weighted to 2001 Australian population) and estimates of the per capita consumption $(\mathrm{kg} \times 10)$ of tobacco in each survey year obtained from excise data for taxation purposes.

1980 and 1995 changes in consumption data reflected the changes in the prevalence of smoking, suggesting that most of the decrease in consumption was due to fewer people smoking. However, between 1995 and 1998 there was a large decrease in the per capita consumption of tobacco that was not reflected by a decrease in smoking prevalence-indeed there was little change in smoking prevalence between 1995 and 1998. The change in consumption suggests there has been a large drop in the number of taxed cigarettes smoked by smokers (see Scollo et al, this issue for information on change in number of cigarettes consumed by smokers between 1995 and $2001^{15}$ ).

Estimates for the prevalence of smoking among men and women in each survey year are given in Table 1. Again, among both men and women the prevalence of smoking declined over the study period. For men the decline in smoking prevalence started from 1980, while for women the decline did not start until after 1983. The differential in smoking prevalence between men and women was greatest in 1980. Since that time the differential in smoking prevalence between men and women has reduced and this was largely due to the reduction in the prevalence of smoking among men in the mid to late 1980s. Combining the data for men and women, logistic regression analyses indicated that after controlling for age, the main effect of year on smoking prevalence was significant $\left(\chi^{2}=525.5, \mathrm{df}=7, \mathrm{p}<0.01\right)$, as was the interaction between year and sex $\left(\chi^{2}=34.3, \mathrm{df}=7, \mathrm{p}<0.01\right)$. Compared with the prevalence of smoking in 2001, there were more smokers in $1998(\mathrm{OR}=1.23,95 \%$ CI 1.16 to 1.3$), 1995(\mathrm{OR}=1.20,95 \% \mathrm{CI}$ 1.12 to 1.29$), 1992(\mathrm{OR}=1.23,95 \% \mathrm{CI} 1.15$ to 1.32$)$, and all surveys in the 1980s. The significant interaction reflects the closing differential in the prevalence of smoking between men and women (see below).

After controlling for sex, a model was fitted to the data testing the significance of the interaction between year and age group. The interaction was significant $\left(\chi^{2}=83.1, \mathrm{df}=28, \mathrm{p}\right.$ $<0.01$ ). Table 1 shows the proportion of men and women smoking in each survey year between 1980 and 2001 for each of the five age groups. The proportion of smokers in each age group declined during the 1980s, stabilised during the early to mid-1990s, and then decreased at the end of the 1990s. In each age group, the prevalence of smoking in 2001 was significantly

Table 1 Proportion of smokers in each sex and age group for each survey year from 1980 to 2001

\begin{tabular}{|c|c|c|c|c|c|c|c|c|c|c|}
\hline & 1980 & 1983 & 1986 & 1989 & 1992 & 1995 & 1998 & 2001 & $\begin{array}{l}\mathrm{p} \text { Value } \\
\text { year }\end{array}$ & Interaction \\
\hline \multicolumn{11}{|l|}{ Sex } \\
\hline Male & $40 \%$ & $38 \%$ & $32 \%$ & $29 \%$ & $28 \%$ & $28 \%$ & $27 \%$ & $25 \%$ & $<0.01$ & \\
\hline Female & $30 \%$ & $29 \%$ & $28 \%$ & $27 \%$ & $24 \%$ & $24 \%$ & $25 \%$ & $21 \%$ & $<0.01$ & \\
\hline People & $35 \%$ & $33 \%$ & $30 \%$ & $27 \%$ & $26 \%$ & $26 \%$ & $26 \%$ & $23 \%$ & $<0.01$ & $<0.01$ \\
\hline OR & 1.8 & 1.7 & 1.5 & 1.3 & 1.2 & 1.2 & 1.2 & 1 & & \\
\hline $95 \% \mathrm{Cl}$ & 1.7 to 2.0 & 1.6 to 1.9 & 1.4 to 1.6 & 1.2 to 1.4 & 1.1 to 1.3 & 1.1 to 1.3 & 1.1 to 1.3 & & & \\
\hline \multicolumn{11}{|l|}{$\begin{array}{l}\text { Age } \\
18-24\end{array}$} \\
\hline Male & $54 \%$ & $43 \%$ & $41 \%$ & $37 \%$ & $35 \%$ & $33 \%$ & $33 \%$ & $31 \%$ & & \\
\hline Female & $41 \%$ & $46 \%$ & $39 \%$ & $39 \%$ & $35 \%$ & $36 \%$ & $31 \%$ & $28 \%$ & & \\
\hline People & $47 \%$ & $45 \%$ & $40 \%$ & $38 \%$ & $35 \%$ & $35 \%$ & $32 \%$ & $30 \%$ & $<0.01$ & .16 \\
\hline OR & 2.1 & 1.9 & 1.6 & 1.5 & 1.3 & 1.3 & 1.1 & 1 & & \\
\hline $95 \% \mathrm{Cl}$ & 1.8 to 2.6 & 1.6 to 2.3 & 1.4 to 1.8 & 1.2 to 1.7 & 1.1 to 1.5 & 1.1 to 1.5 & 1.0 to 1.3 & & & \\
\hline \multicolumn{11}{|l|}{$25-29$} \\
\hline Male & $46 \%$ & $48 \%$ & $38 \%$ & $37 \%$ & $36 \%$ & $34 \%$ & $32 \%$ & $33 \%$ & & \\
\hline Female & $42 \%$ & $34 \%$ & $39 \%$ & $35 \%$ & $33 \%$ & $34 \%$ & $35 \%$ & $27 \%$ & & \\
\hline People & $44 \%$ & $41 \%$ & $39 \%$ & $36 \%$ & $35 \%$ & $35 \%$ & $34 \%$ & $30 \%$ & $<0.01$ & 0.04 \\
\hline OR & 1.82 & 1.59 & 1.48 & 1.29 & 1.22 & 1.23 & 1.18 & 1 & & \\
\hline $95 \% \mathrm{Cl}$ & 1.5 to 2.3 & 1.3 to 1.9 & 1.2 to 1.8 & 1.1 to 1.6 & 1.0 to 1.5 & 1.0 to 1.5 & 0.99 to 1.4 & & & \\
\hline \multicolumn{11}{|l|}{$30-39$} \\
\hline Male & $40 \%$ & $41 \%$ & $33 \%$ & $35 \%$ & $32 \%$ & $32 \%$ & $34 \%$ & $30 \%$ & & \\
\hline Female & $35 \%$ & $31 \%$ & $30 \%$ & $29 \%$ & $28 \%$ & $30 \%$ & $32 \%$ & $26 \%$ & & \\
\hline People & $37 \%$ & $36 \%$ & $32 \%$ & $32 \%$ & $30 \%$ & $39 \%$ & $33 \%$ & $28 \%$ & $<0.01$ & 0.51 \\
\hline OR & 1.54 & 1.43 & 1.17 & 1.23 & 1.09 & 1.13 & 1.27 & 1 & & \\
\hline $95 \% \mathrm{Cl}$ & 1.3 to 1.8 & 1.2 to 1.6 & 1.1 to 1.3 & 1.1 to 1.4 & 1.0 to 1.3 & 1.0 to 1.3 & 1.1 to 1.4 & & & \\
\hline \multicolumn{11}{|l|}{$40-59$} \\
\hline Male & $44 \%$ & $38 \%$ & $32 \%$ & $25 \%$ & $28 \%$ & $28 \%$ & $26 \%$ & $24 \%$ & & \\
\hline Female & $27 \%$ & $30 \%$ & $27 \%$ & $25 \%$ & $23 \%$ & $21 \%$ & $25 \%$ & $20 \%$ & & \\
\hline People & $36 \%$ & $34 \%$ & $29 \%$ & $25 \%$ & $26 \%$ & $24 \%$ & $26 \%$ & $22 \%$ & $<0.01$ & $<0.01$ \\
\hline OR & 1.98 & 1.83 & 1.51 & 1.19 & 1.24 & 1.16 & 1.23 & 1 & & \\
\hline $95 \% \mathrm{Cl}$ & 1.8 to 2.3 & 1.6 to 2.1 & 1.4 to 1.7 & 1.5 to 1.3 & 1.1 to 1.4 & 1.0 to 1.3 & 1.1 to 1.4 & & & \\
\hline \multicolumn{11}{|l|}{$60+$} \\
\hline Male & $22 \%$ & $26 \%$ & $22 \%$ & $18 \%$ & $16 \%$ & $15 \%$ & $12 \%$ & $11 \%$ & & \\
\hline Female & $18 \%$ & $17 \%$ & $17 \%$ & $15 \%$ & $12 \%$ & $12 \%$ & $12 \%$ & $8 \%$ & & \\
\hline People & $20 \%$ & $21 \%$ & $19 \%$ & $17 \%$ & $14 \%$ & $13 \%$ & $12 \%$ & $10 \%$ & $<0.01$ & 0.46 \\
\hline OR & 2.3 & 2.5 & 2.3 & 1.9 & 1.5 & 1.4 & 1. 3 & 1 & & \\
\hline $95 \% \mathrm{Cl}$ & 1.9 to 2.8 & 2.1 to 3.0 & 1.9 to 2.6 & 1.5 to 2.3 & 1.2 to 1.8 & 1.2 to 1.8 & 1.1 to 1.5 & & & \\
\hline
\end{tabular}


Table 2 Proportion of smokers in each occupation group in each survey year from 1980 to 2001

\begin{tabular}{|c|c|c|c|c|c|c|c|c|c|}
\hline & 1980 & 1983 & 1986 & 1989 & 1992 & 1995 & 1998 & 2001 & $\begin{array}{l}p \text { Value } \\
\text { year }\end{array}$ \\
\hline \multicolumn{10}{|c|}{ Upper white } \\
\hline People & $32 \%$ & $25 \%$ & $23 \%$ & $19 \%$ & $19 \%$ & $19 \%$ & $18 \%$ & $16 \%$ & \multirow[t]{3}{*}{$<0.01$} \\
\hline OR & & & & 1.2 & & 1.2 & 1. 2 & 1 & \\
\hline $95 \% \mathrm{Cl}$ & $(2.1$ to 3.1$)$ & (1.4 to 2.3 ) & (1.3 to 1.9 ) & $(1.0$ to 1.6$)$ & $(1.0$ to 1.5$)$ & $(1.0$ to 1.5$)$ & (1.0 to 1.4 ) & & \\
\hline \multicolumn{10}{|c|}{ Lower white } \\
\hline People & $37 \%$ & $36 \%$ & $29 \%$ & $27 \%$ & $26 \%$ & $23 \%$ & $24 \%$ & $25 \%$ & \multirow{3}{*}{$<0.01$} \\
\hline OR & & & & & & & 0.9 & 1 & \\
\hline $95 \% \mathrm{Cl}$ & (1.5 to 2.0 ) & (1.5 to 1.9 ) & (1.1 to 1.4 ) & (1.0 to 1.3 ) & (0.9 to 1.2 ) & $(0.8$ to 1.0$)$ & (0.8 to 1.1$)$ & & \\
\hline \multicolumn{10}{|l|}{ Upper blue } \\
\hline People & $47 \%$ & $40 \%$ & $36 \%$ & $33 \%$ & $31 \%$ & $33 \%$ & $29 \%$ & $30 \%$ & \multirow[t]{3}{*}{$<0.01$} \\
\hline OR & 2.1 & 1.6 & 1.3 & 1.2 & 1.1 & 1.1 & 1.0 & 1 & \\
\hline $95 \% \mathrm{Cl}$ & (1.7 to 2.6$)$ & (1.3 to 2.0$)$ & $(1.1$ to 1.6$)$ & (1.0 to 1.5 ) & (0.9 to 1.3 ) & (0.9 to 1.4 ) & (0.8 to 1.2 ) & & \\
\hline \multicolumn{10}{|l|}{ Lower blue } \\
\hline People & $52 \%$ & $46 \%$ & $44 \%$ & $39 \%$ & $36 \%$ & $41 \%$ & $40 \%$ & $36 \%$ & \multirow[t]{3}{*}{$<0.01$} \\
\hline OR & & 1.4 & 1.4 & & & 1.2 & 1.2 & 1 & \\
\hline $95 \% \mathrm{Cl}$ & (1.6 to 2.4$)$ & (1.2 to 1.8 ) & (1.2 to 1.6$)$ & $(0.9$ to 1.4$)$ & (0.8 to 1.2$)$ & (1.0 to 1.4$)$ & (1.0 to 1.4 ) & & \\
\hline \multicolumn{10}{|c|}{ Not in paid work } \\
\hline People & $27 \%$ & $30 \%$ & $27 \%$ & $25 \%$ & $24 \%$ & $24 \%$ & $25 \%$ & $20 \%$ & \multirow[t]{3}{*}{$<0.01$} \\
\hline$O R$ & 1.7 & 1.8 & 1.6 & 1.5 & 1.3 & 1.3 & 1.4 & 1 & \\
\hline $95 \% \mathrm{Cl}$ & (1.5 to 1.9 ) & $(1.6$ to 2.0$)$ & (1.5 to 1.8 ) & (1.3 to 1.6$)$ & (1.2 to 1.5$)$ & (1.2 to 1.5$)$ & (1.3 to 1.5$)$ & & \\
\hline
\end{tabular}

different from that found in 1998, although this difference was of borderline significance for the 18-24 year olds (1998, $\mathrm{OR}=1.1,95 \%$ CI 1.0 to 1.3 ).

After controlling for sex and age, a model was fitted to the data testing the significance of the interaction between year and occupation. The interaction was significant $\left(\chi^{2}=83.06\right.$, $\mathrm{df}=1, \mathrm{p}<0.01)$. Table 2 shows the proportion of smokers in each of the five levels of occupation for each survey year. For each survey year, smoking prevalence was lowest among upper white collar workers and highest among lower blue collar workers. However, for each occupation the proportion of smokers in 1980 was about double the proportion found in 2001. Similar to the patterns seen for age, for each occupation smoking prevalence declined in the 1980s and stabilised during the 1990s. Although the prevalence of smoking among upper white collar workers in 2001 was significantly different from those found in the 1980s, the differences between the 2001 estimate and the estimates for 1992, 1995, and 1998 were of borderline significance (that is, 95\% CI includes 1.0). For blue collar workers, although the 2001 estimate of smoking was lower than those found in other survey years, analyses suggest that the prevalence of smoking in 2001 was not significantly different from that found in 1989, 1992, 1995, and 1998. However, smoking prevalence in these groups was lower in 2001 than in the mid-1980s (see Table 2).

Given the interactions between year and the sociodemographic variables noted above, it was of interest to explore whether the differential in smoking prevalence for the different levels of the sociodemographic variables had changed between different groups over the survey period. Table 3 shows for sex, age, and socioeconomic status the odds ratio for smoking in each group membership category across all survey years. Odds ratios in the table are adjusted for all variables in the table. The information in the table allows us to examine whether the differential in smoking rates between different levels of a sociodemographic variable (that is women compared to men, older compared to younger people, and lower blue collar workers compared to upper white collar workers) have changed across survey years. As the table shows, the odds for smoking among women were about one third less than those for men in 1980 (OR=0.63, 95\% CI 0.55 to 0.72 ), but only about $10 \%$ in 1989 (OR=0.90, $95 \%$ CI 0.79 to $1.01)$, which was not a significant difference. However, by 2001 the difference in the odds for men and women smoking was significant again ( $\mathrm{OR}=0.78,95 \% \mathrm{CI} 0.74$ to 0.84$)$. Despite this, the differential in smoking between men and women was significantly less in 2001 than it was in 1980 ( $z=3.0, p<0.01)$.

Table 3 also shows for each survey year the odds ratios for smoking in each age group compared with the 18-24 year olds. Across the years, the proportion of 18-24 year olds smoking was no different from that found in the 25-29 year old age group. The difference in the proportion of smokers among the 30-39 year olds and the 18-24 year olds decreased over the survey years, so that by 1995 this difference was not significant (1995, OR $=0.85,95 \%$ CI 0.68 to 1.02 ). The difference in the odds ratios for 30-39 year olds for 1980 and 2001 was significant $(\mathrm{z}=2.6, \mathrm{p}<0.01)$. Between 2001 and 1980 there was no change in the odds ratios for $40-59$ year olds $(z=0.66, p>0.05)$ or for those over $60(z=0.66, p>0.05)$, indicating that the relative difference in the proportion of smokers among 18-24 year olds and these two age groups was similar across the survey years.

The odds ratios for smoking in each occupation group compared with upper white collar workers is also shown in Table 3. For all years except 1980, the proportion of smokers among upper white collar workers was significantly lower than in all other occupation groups. The odds ratio for smokers among lower white collar workers compared with upper white collar workers in 2001 was greater than that found in $1980(\mathrm{z}=3.7$, $\mathrm{p}<0.01$ ), but did not differ significantly from those found in all other survey years except for 1995, where the difference was significant $(z=2.30, p<0.01)$. A similar result was found when comparing the odds ratios for upper blue collar workers over survey years. The difference in the odds ratio for upper blue collar workers smoking compared with upper white collar in 2001 was of borderline significance when compared with that found in $1980(\mathrm{z}=1.97, \mathrm{p}<0.05)$, but was not different from the odds ratio found in any other year. For lower blue collar workers, the results suggest that the odds ratio for smoking in this group compared with the odds for smoking among upper white collar workers in 1980 was significantly different from those found in both $1998(\mathrm{z}=2.4, \mathrm{p}<0.01)$ and $2001(\mathrm{z}=2.4, \mathrm{p}<0.01)$. The pattern of results suggest that the differential in the prevalence of smoking between occupation groups had widened between 1980 and 2001.

\section{DISCUSSION}

There has been a continual decline in the prevalence of smoking among Australian men since 1980 and Australian women since 1983. Some of the largest declines in the prevalence of 
Table 3 Adjusted odds ratios from logistic regression of smoking status on sociodemographic variables for each survey year

\begin{tabular}{|c|c|c|c|c|c|c|c|c|}
\hline & 1980 & 1983 & 1986 & 1989 & 1992 & 1995 & 1998 & 2001 \\
\hline \multicolumn{9}{|l|}{ Sex } \\
\hline Males & 1 & 1 & 1 & 1 & 1 & 1 & 1 & 1 \\
\hline $\begin{array}{l}\text { Females } \\
95 \% \mathrm{Cl}\end{array}$ & $\begin{array}{l}0.6 \\
(0.5 \text { to } 0.7)\end{array}$ & $\begin{array}{l}0.7 \\
(0.6 \text { to } 0.8)\end{array}$ & $\begin{array}{l}0.8 \\
(0.7 \text { to } 0.9)\end{array}$ & $\begin{array}{l}0.9 \\
(0.8 \text { to } 1.0)\end{array}$ & $\begin{array}{l}0.8 \\
(0.7 \text { to } 0.9)\end{array}$ & $\begin{array}{l}0.8 \\
(0.7 \text { to } 0.9)\end{array}$ & $\begin{array}{l}1.0 \\
(0.9 \text { to } 1.1)\end{array}$ & $\begin{array}{l}0.8 \\
(0.7 \text { to } 0.9)\end{array}$ \\
\hline \multicolumn{9}{|l|}{$\mathrm{Age}^{*}$} \\
\hline $18-24$ & 1 & 1 & 1 & 1 & 1 & 1 & 1 & 1 \\
\hline $\begin{array}{l}25-29 \\
(95 \% \mathrm{Cl})\end{array}$ & $\begin{array}{l}0.88 \\
(0.7 \text { to } 1.2)\end{array}$ & $\begin{array}{l}0.85 \\
(0.7 \text { to } 1.1)\end{array}$ & $\begin{array}{l}0.96 \\
(0.8 \text { to } 1.2)\end{array}$ & $\begin{array}{l}0.90 \\
(0.7 \text { to } 1.2)\end{array}$ & $\begin{array}{l}0.97 \\
(0.8 \text { to } 1.2)\end{array}$ & $\begin{array}{l}1.00 \\
(0.8 \text { to } 1.3)\end{array}$ & $\begin{array}{l}1.08 \\
(0.9 \text { to } 1.3)\end{array}$ & $\begin{array}{l}1.03 \\
(0.91 \text { to } 1.2)\end{array}$ \\
\hline $\begin{array}{l}30-39 \\
(95 \% \mathrm{Cl})\end{array}$ & $\begin{array}{l}0.67 \\
(0.5 \text { to } 0.8)\end{array}$ & $\begin{array}{l}0.69 \\
(0.6 \text { to } 0.8)\end{array}$ & $\begin{array}{l}0.69 \\
(0.6 \text { to } 0.9)\end{array}$ & $\begin{array}{l}77 \\
(0.6 \text { to } 0.9)\end{array}$ & $\begin{array}{l}0.78 \\
(0.6 \text { to } 0.9)\end{array}$ & $\begin{array}{l}0.84 \\
(0.7 \text { to } 1.0)\end{array}$ & $\begin{array}{l}1.1 \\
(0.9 \text { to } 1.2)\end{array}$ & $\begin{array}{l}0.93 \\
(0.8 \text { to } 1.0)\end{array}$ \\
\hline $\begin{array}{c}40-59 \\
(95 \% \mathrm{Cl})\end{array}$ & $\begin{array}{l}0.62 \\
(0.50 \text { to } 0.8)\end{array}$ & $\begin{array}{l}0.63 \\
(0.5 \text { to } 0.8)\end{array}$ & $\begin{array}{l}0.63 \\
(0.5 \text { to } 0.7)\end{array}$ & $\begin{array}{l}0.54 \\
(0.5 \text { to } 0.7)\end{array}$ & $\begin{array}{l}0.63 \\
(0.5 \text { to } 0.8)\end{array}$ & $\begin{array}{l}0.61 \\
(0.1 \text { to } 0.7)\end{array}$ & $\begin{array}{l}0.74 \\
(0.6 \text { to } 0.9)\end{array}$ & $\begin{array}{l}0.66 \\
(0.6 \text { to } 0.7)\end{array}$ \\
\hline $\begin{array}{l}60+ \\
(95 \% \mathrm{Cl})\end{array}$ & $\begin{array}{l}0.28 \\
(0.2 \text { to } 0.4)\end{array}$ & $\begin{array}{l}0.33 \\
(0.3 \text { to } 0.4)\end{array}$ & $\begin{array}{l}0.36 \\
(0.3 \text { to } 0.4)\end{array}$ & $\begin{array}{l}0.32 \\
(0.3 \text { to } 0.4)\end{array}$ & $\begin{array}{l}0.29 \\
(0.2 \text { to } 0.4)\end{array}$ & $\begin{array}{l}0.29 \\
(0.2 \text { to } 0.4)\end{array}$ & $\begin{array}{l}0.29 \\
(3 \text { to } 45)\end{array}$ & $\begin{array}{l}0.26 \\
(0.2 \text { to } 0.3)\end{array}$ \\
\hline \multicolumn{9}{|l|}{ Occupation† } \\
\hline Upper white collar & 1 & 1 & 1 & 1 & 1 & 1 & 1 & 1 \\
\hline $\begin{array}{l}\text { Lower white collar } \\
(95 \% \mathrm{CI})\end{array}$ & $\begin{array}{l}1.1 \\
(0.9 \text { to } 1.4)\end{array}$ & $\begin{array}{l}1.8 \\
(1.4 \text { to } 2.3)\end{array}$ & $\begin{array}{l}1.4 \\
(1.1 \text { to } 1.7)\end{array}$ & $\begin{array}{l}1.5 \\
(1.2 \text { to } 2.0)\end{array}$ & $\begin{array}{l}1.5 \\
(1.2 \text { to } 2.0)\end{array}$ & $\begin{array}{l}1.3 \\
(1.0 \text { to } 1.7)\end{array}$ & $\begin{array}{l}1.4 \\
(1.2 \text { to } 1.7)\end{array}$ & $\begin{array}{l}1.8 \\
(1.6 \text { to } 2.0)\end{array}$ \\
\hline $\begin{array}{l}\text { Upper blue collar } \\
(95 \% \mathrm{Cl})\end{array}$ & $\begin{array}{l}1.6 \\
(1.2 \text { to } 2.1)\end{array}$ & $\begin{array}{l}1.8 \\
(1.3 \text { to } 2.3)\end{array}$ & $\begin{array}{l}1.7 \\
(1.3 \text { to } 2.1)\end{array}$ & $\begin{array}{l}1.9 \\
(1.5 \text { to } 2.6)\end{array}$ & $\begin{array}{l}1.8 \\
(1.3 \text { to } 2.3)\end{array}$ & $\begin{array}{l}1.9 \\
(1.5 \text { to } 2.5)\end{array}$ & $\begin{array}{l}1.8 \\
(1.4 \text { to } 2.2)\end{array}$ & $\begin{array}{l}2.1 \\
(1.9 \text { to } 2.4)\end{array}$ \\
\hline $\begin{array}{l}\text { Lower blue collar } \\
(95 \% \mathrm{CI})\end{array}$ & $\begin{array}{l}2.0 \\
(1.5 \text { to } 2.6)\end{array}$ & $\begin{array}{l}2.4 \\
(1.8 \text { to } 3.1)\end{array}$ & $\begin{array}{l}2.4 \\
(2.0 \text { to } 3.0)\end{array}$ & $\begin{array}{l}2.5 \\
(1.9 \text { to } 3.3)\end{array}$ & $\begin{array}{l}2.4 \\
(1.8 \text { to } 3.1)\end{array}$ & $\begin{array}{l}2.8 \\
(2.2 \text { to } 3.6)\end{array}$ & $\begin{array}{l}3.0 \\
(2.4 \text { to } 3.6)\end{array}$ & $\begin{array}{l}2.8 \\
(2.5 \text { to } 3.2)\end{array}$ \\
\hline \multicolumn{9}{|l|}{ Not in paid } \\
\hline $\begin{array}{l}\text { employment } \\
\text { (95\% CI) }\end{array}$ & $\begin{array}{l}1.1 \\
(0.9 \text { to } 1.3)\end{array}$ & $\begin{array}{l}1.9 \\
(1.5 \text { to } 2.4)\end{array}$ & $\begin{array}{l}1.7 \\
\text { (1.4 to } 2.0)\end{array}$ & $\begin{array}{l}1.9 \\
(1.5 \text { to } 2.5)\end{array}$ & $\begin{array}{l}2.2 \\
(1.7 \text { to } 2.8)\end{array}$ & $\begin{array}{l}2.0 \\
(1.6 \text { to } 2.6)\end{array}$ & $\begin{array}{l}2.5 \\
(2.0 \text { to } 3.0)\end{array}$ & $\begin{array}{l}2.0 \\
(1.8 \text { to } 2.3)\end{array}$ \\
\hline
\end{tabular}

smoking among men seen over the 21 year period reported here occurred between 1983 and 1986. For instance, smoking prevalence declined among men by 15\% between 1983 and 1986 (from $38 \%$ to $32 \%$ ) while prevalence declined by $7 \%$ between 1998 and 2001 (from 27\% to 25\%). The relatively large declines in smoking prevalence seen in the early to mid1980s coincide with the onset of well funded public heath campaigns promoting quitting in Australia and may reflect the impact of these campaigns ${ }^{13}$ and their uptake across the country. ${ }^{11}$ However, as reported by Hill et al, the decline in the prevalence of smoking among Australian adults had stalled by the mid-1990s. ${ }^{8}$ Hill et al suggested that this stalling was due in part to a drying up of funds to tobacco control programmes in the early to mid 1990s and postulated that smoking rates would only decline again when funding to tobacco control programmes increased. ${ }^{8}$ With the advent of the National Tobacco Campaign in 1997, funding to tobacco control programmes increased from 26 cents per adult in 1996 to 55 cents per adult in 1998 and 49 cents per adult in $2001 .^{21}$ In addition to this increase in funding, a coordinated national approach was taken to tobacco control with all jurisdictions working towards promoting the same message and sharing both a national marketing strategy and resources such as the Quitline. Evaluation studies for this campaign suggested that this increase in activity was associated with a decline in smoking prevalence. ${ }^{22}$ Although these telephone surveys were designed for programme evaluation purposes, they nevertheless provided estimates of prevalence and trends consistent with those we report above, that is proportion of adults smoking at least weekly. These surveys indicated that the prevalence of smoking in Australia declined in the late 1990s from $23.5 \%$ in May 1997 to $19.5 \%$ in November $2001 .{ }^{23}$ Wakefield et al (this issue) also showed that the campaign was associated with sustained increase in smokers' knowledge of the health consequences of smoking and an increase in positive attitudes and intention to quit smoking. ${ }^{16}$

The decline in smoking prevalence seen between 1998 and 2001 may reflect the impact of this increased tobacco control activity. However, it may also reflect the impact changes to the formula for calculating tobacco tax had on consumption and prevalence. Scollo et al suggest that at least two thirds of the decline in smoking participation between 1999 and 2000 could be due to increased taxes on cigarettes. ${ }^{15}$ Taking account of tobacco consumption data collected independently for taxation purposes, it seems that changes in the rate of tobacco use by smokers (consumption) may have exceeded in magnitude changes in prevalence (proportion of the population smoking). If so, it seems plausible to attribute reduction in consumption to both the prohibiting of smoking in many public places and effective price rises. Because "lighter" smokers may quit smoking more easily than heavy consumers of tobacco, sustained reductions in daily consumption may set the stage for later more successful quit attempts triggered and supported by comprehensive quit campaigns.

Examination of the trends in smoking prevalence within the different sociodemographic groups showed some gains and losses over the 21 year period of this study. Firstly, for sex, the analyses presented in table 3 suggested that the differential in smoking between men and women changed over the period of this study and by 2001 the differential had reduced. This was largely due to a greater proportion of male smokers quitting compared with the proportion of female smokers in the 1980s. Among the different age groups, although over the years there was no change in the differentials in smoking prevalence between the youngest age group (18-24 year olds) and those over 40 years of age, there was some change between the two youngest age groups. In 1980 smoking was more common among people aged 18-24 than among those aged 30-39. By 1995 this difference was no longer significant. This change was due to the proportion of smokers among the youngest age group decreasing at a slightly greater rate than that seen among the 30-39 year olds. These findings suggest that tobacco control activities in the 1990s have been particularly successful among adolescents and young adults and reflect lower levels of smoking uptake in these groups in the late 1980 s and early $1990 \mathrm{~s}^{24}$ It is noted that the analyses presented here and the interpretation of these analyses made above treat each age group in each survey year as independent groups. In reality this is not the case as members of an age group are linked across years by the fact that they are 
members of a birth cohort. That is, the 18-24 year olds surveyed in 1983 are the members of the 36-39 age group surveyed in 2001. Part of the reason for the growing difference in smoking rates between 18-24 year olds and the 30-39 year olds might be that the 18-24 year olds in 1983 were not giving up smoking as they aged, while the cohort of adolescents moving into the 18-24 year old age group were not taking up smoking to the same extent as previous cohorts of adolescents due to increased controls on access to cigarettes, increased education, and increasing price of cigarettes.

Trends in the prevalence of smoking in different occupation groups present more troubling findings. On one level we can feel assured that the prevalence of smoking among all occupation groups was lower in 2001 than in 1980. This is a positive finding as it means that all sociodemographic groups were hearing and heeding the quit smoking message. However, we must acknowledge that most of this decrease occurred during the 1980s. In addition, our results suggest that the differential in smoking rates between upper white collar workers and blue collar workers had increased over the 21 year period of this study. This increase was largely due to smoking prevalence decreasing at a greater rate among upper white collar workers (these workers were nearly three times more likely to smoke in 1980 compared with 2001), compared with other types of workers (where there was only a twofold difference in the odds of smoking from 1980 to 2001). It was also because there was no decrease in the prevalence of smoking among lower blue collar workers between 1992 and 1995. This "stalling" began at a time when funding to tobacco control programmes was at its lowest level and when there was no sustained presence of the quit smoking message on television or radio. ${ }^{8}$ It also occurred at a time when Australia experienced a severe economic downturn. Because the prevalence of smoking remained relatively high in lower blue collar workers in 1998 and did not drop to 1992 levels until 2001, it seems any effect of tobacco control efforts in the late 1990s were minimal or delayed in this population group. One of the major tobacco control efforts in Australia in the late 1990s was the National Tobacco Campaign (NTC). Wakefield et al (this issue) showed that the NTC was effective at reaching a broad cross section of the Australian community and according to the evaluation studies did have an impact on the prevalence of smoking in all socioeconomic groups. ${ }^{16}$ These findings coupled with the data presented here suggest that any impact the NTC had on the smoking behaviour of people with lower blue collar occupations may have been delayed. However, as indicated above, the decrease in prevalence between 1998 and 2001 coincides with a substantial increase in the price of cigarettes due to changes in the way taxation was levied on tobacco in 1999. Scollo et al (this issue) show that these price rises were effective at reducing both consumption and prevalence of smoking among lower blue collar workers between 1999 and 2000. ${ }^{15}$ Taken together, these data suggest that strong tobacco control programmes that include media campaigns that promote quitting, real increases in the price of cigarettes, and increased restrictions on smoking in public places, can work to reduce smoking among all socioeconomic groups and can be particularly effective with the lower socioeconomic groups.

Do our data provide any evidence of a "trickle down" effect, in which reductions in prevalence in upper socioeconomic groups are followed after a time lag by reductions in lower socioeconomic groups? Table 3 suggests that at least until 1992 there was a 6 year lag in an occupation group achieving the prevalence of smoking seen in the occupation group of the next higher level. That is, although the prevalence of smoking among lower white collar workers was $37 \%$ in 1980, it was not until 1986 that this prevalence was found among upper blue collar workers. Similarly, $40 \%$ of upper blue collar workers were smoking in 1983 and it was not until 1989 that a similar prevalence level was seen among lower blue collar workers. This pattern dissipated in 1995 and 1998 with the increase in smoking prevalence in the lower blue collar workers and the lack of change in smoking prevalence seen in the other groups. The data from 2001 suggest, however, that at least among the lower blue collar workers this pattern may be emerging again. Future studies need to confirm the suggestion that changes in smoking prevalence between different socioeconomic groups reflect time lags in the uptake of this behaviour.

It must be noted that the widening differential in the smoking rates between upper and lower socioeconomic groups has been seen in other Western countries, suggesting it is not solely an Australian phenomenon. ${ }^{25-26}$ This widening differential in smoking rates might be indicative of the widening economic difference between these two groups that has occurred in Australia since the 1980s. ${ }^{27-28}$ These findings suggest an urgent need for tobacco control programmes in Australia to determine the most appropriate strategies for encouraging smoking cessation among these groups.

We have speculated that the decline in the prevalence of smoking seen in the 21 year period between 1980 and 2001 in Australia is due to the tobacco control efforts in this country. We note, however, that other societal changes may have had some impact on the prevalence of smoking during this time period. The education level of the population has increased over this time period and as smoking prevalence has been shown to be inversely related to education level, ${ }^{6-8}$ this may explain some of the decrease in smoking prevalence, especially among the younger age groups. In addition, population increases due to migration may also help explain some of the decrease in smoking prevalence. Because of the "healthy migrant effect" ${ }^{\prime 29-30}$ it could be speculated that increases to the population by migration will reduce smoking prevalence as migrants will be less likely to smoke. However, as previous work $^{31}$ has suggested that the prevalence of smoking among people born in the United Kingdom/Ireland and Western Europe (about half of people who say they were born overseas) is similar to that of Australian born adults, it seems unlikely that changes in the population due to immigration would explain much of the decline in smoking prevalence.

We estimate that $23 \%$ of Australian adults smoked regularly in 2001. This estimate is similar to that found in a study on the health of Australians conducted in 2001 by the Australian Bureau of Statistics where face to face interviews were conducted. ${ }^{32}$ That study found $24 \%$ of the population smoked regularly (defined as daily or occasional use of tobacco). The similarity of the two estimates for the prevalence of regular cigarette smoking among Australian adults in 2001 makes us confident that the 2001 estimate reported here and our analyses of trends in smoking are valid.

Authors' affiliations

V White, D Hill, I Bobevski, Centre for Behavioural Research in Cancer, Cancer Control Research Institute, The Cancer Council Victoria, Australia M Siahpush, VicHealth Centre for Tobacco Control, The Cancer Council Victoria, Australia

\section{REFERENCES}

1 Gray NJ, Hill DJ. Patterns of tobacco smoking in Australia. Med J Aust 1975;2:819-22.

2 Gray NJ, Hill DJ. Patterns of tobacco smoking in Australia: 2. Med J Aust 1977;2:329-30.

3 Hill DJ, Gray NJ. Patterns of tobacco smoking in Australia: 3. Med J Aust $1982 ; 1: 23-5$

4 Hill D, Gray N. Australian patterns of tobacco smoking and related health beliefs in 1983. Community Health Studies 1984;8:307-16.

5 Hill D. Australian patterns of tobacco smoking in 1986. Med J Aust 1988; 149:6-10.

6 Hill DJ, White VM, Gray NJ. Australian patterns of tobacco smoking in 1989. Med J Aust 1991;154:797-801.

7 Hill DJ, White VM. Australian adult smoking prevalence in 1992. Aust J Public Health 1995; 19:305-8.

8 Hill D, White VM, Scollo MM. Smoking behaviours of Australian adults in 1995: trends and concerns. Med J Aust 1998;168:209-13.

9 Gray N, Daube M, eds. Guidelines for smoking control. 2nd edn. UICC technical Report Series vol 52. Geneva: UICC, 1980. 
10 Centers for Disease Control and Prevention. Best practices for comprehensive tobacco control programs. August 1999. Atlanta, GA: US Department of Health and Human Services, Centers for Disease Control and Prevention, National Center for Chronic Disease Prevention and Health Promotion, Office on Smoking and Health, August 1999. www.cdc.gov/tobacco/bestprac.htm

11 Winstanley M, Woodward S, Walker N. Tobacco in Australia: facts and issues. 2nd edn. Melbourne: Victorian Smoking and Health Program, 1995.

12 Borland R, Hill D. Initial impact of the new Australian tobacco warnings on knowledge and beliefs. Tob Control 1997;6:317-25.

13 Pierce J, Dwyer T, Frape G, et al. Evaluation of the Sydney "Quit for Life" anti-smoking campaign. Med J Australia 1986;144:341-7.

14 Pierce J, Macaskill P, Hill D. Long term effectiveness of mass media led anti-smoking campaigns in Australia. Am J Public Health 1990:80:565-9

15 Scollo $M$, Younie S, Wakefield $M$, et al. Impact of tobacco tax reforms on tobacco prices and tobacco use in Australia. Tob Control 2003;12(suppl II);ii59-66.

16 Wakefield M, Freeman J, Donovan R. Recall and response of smokers and recent quitters to the Australian National Tobacco Campaign. Tob Control 2003;12(suppl II);ii 15-22.

17 Hill D, White V, Gray NJ. Measures of tobacco smoking in Australia 1974-1986. By means of a Standard Method. Med J Aust 1988;149:10-2.

18 AlHW. 2001 National Drug Strategy Household Survey: detailed findings. Drug Statistics Series no 11. Canberra: AlHW.

19 Mullins R, Hill D, Borland R. Changing the way smoking is measured among Australian adults. In: Trotter L, Letcher T, eds. Quit Evaluation Studies Vol 10. Melbourne: Anti-Cancer Council of Victoria 2000:59-66.

20 Scollo M. Estimated total consumption of tobacco products for Australia selected years - based on tobacco products duties, unpublished data. Melbourne: VicHealth Centre for Tobacco Control, 2002.

21 Wakefield $\mathbf{M}$, Freeman J, Inglis $\mathbf{G}$. Changes associated with the National Tobacco Campaign: results of the third and fourth follow-up surveys. Melbourne: Centre for Behavioural Research in Cancer, The Cancer Council Victoria (In press)

22 Tan N, Wakefield M, Freeman J. Changes associated with the National Tobacco Campaign: results of the second follow-up survey. In: Hassard K, ed. Australia's National Tobacco Campaign: evaluation report volume two. Canberra: Commonwealth Department of Health and Aged Care, Commonwealth of Australia, 2000.

23 Wakefield M, Freeman J, Bobevski I. Changes associated with the National Tobacco Campaign: preliminary report on smoking prevalence and consumption, 1997-2001. Centre for Behavioural Research in Cancer (unpublished report prepared for the Commonwealth Department of Health and Ageing, Canberra) 2002.

24 Hill DJ, White VM, Williams RM, et al. Tobacco and alcohol use among Australian secondary school students in 1990. Med J Aust 1993; 158:228-34.

25 Marsh A, McKay S. Poor Smokers. London: Policy Studies Institute, 1994.

26 Jarvis MJ, Wardle J. Social patterning of individual health behaviours: the case of cigarette smoking. In: Marmot M, Wilkinson RG, eds. Social determinants of health. Oxford: Oxford University Press, 1999.

27 Harding A, Greenwell H. Trends in income and expenditure inequality in the 1980s and 1990s: a re-examination and further analysis. Canberra: National Centre for Social and Economic Modelling, 2002.

28 Australian Bureau of Statistics. Australian social trends (4102.0) Canberra: AGPS, 2001

29 Wooden M, Holton R, Hugo G, et al. Australian immigration: a survey of the issues. 2nd edn. Canberra: AGPS, 1994.

30 Australian Institute of Health and Welfare. Australia's health 2000: the seventh biennial health report of the Australian Institute of Health and Welfare. Canberra: AlHW, 2000.

31 Siahpush $M$, Borland R. Sociodemographic variations in smoking status among Australians aged over 18: multivariate results from the 1995 National Health Survey. Aust NZ J Public Health 2001;25:438-42.

32 Australian Bureau of Statistics National Health Survey-Summary of Results Australia 2001(4364.0) Canberra: AGPS, 2002. 